\title{
Structure and Development of Viruses as Observed in the Electron Microscope
}

\author{
IX. Entry of Parainfluenza I (Sendai) Virus \\ COUNCILMAN MORGAN AND CALDERON HOWE \\ Department of Microbiology, College of Physicians and Surgeons, \\ Columbia University, New York, New York 10032
}

Received for publication 12 July 1968

\begin{abstract}
After attachment, the uncoating of Sendai virus, which was accompanied by dissolution of the plasma membrane and fusion of virus to cell, proceeded quickly. Nucleoprotein filaments were found at stages of transit from virus to cytoplasm.
\end{abstract}

After attachment of influenza virus to the cell, the following events have been shown to occur in rapid succession. The virion is uncoated at the cellular surface, the cytoplasmic membrane is dissolved, and the viral core ruptures with consequent release of nucleoprotein into the cytoplasm (6). It was suggested that this mechanism of entry had heretofore escaped attention simply because it occurred so quickly. Indeed, the several stages of the process were observed only when virus was allowed to adsorb to the cells at $4 \mathrm{C}$ and then was studied carefully during the first 5 min after the environmental temperature was raised to $37 \mathrm{C}$. In the light of the findings with influenza virus, it was decided to investigate, by similar methods, the manner in which parainfluenza type 1 (Sendai) virus gains entry into the cell.

\section{Materials AND Methods}

Type 1 parainfluenza (Sendai) virus was propagated in the chorioallantoic sac of 11-day-old chicken embryos. Infected chorioallantoic fluid was first clarified by low-speed centrifugation, and the virus was then sedimented in an ultracentrifuge at $100,000 \times g$ for $2 \mathrm{hr}$. Small fragments of shell with attached chorioallantoic membrane from 11-day-old chicken embryos were placed in suspensions of crude concentrated virus $\left(2 \times 10^{5}\right.$ to $5 \times 10^{5}$ hemagglutinating units $\left./ \mathrm{ml}\right)$ and were kept at $4 \mathrm{C}$ for $1 \mathrm{hr}$. The membranes were then washed and placed in Earle's balanced salt solution warmed to $37 \mathrm{C}$. After incubation for 2, 4, 5, 6, and $10 \mathrm{~min}$, the membranes were removed from the shells, fixed for $1 \mathrm{hr}$ in $1 \%$ glutaraldehyde, washed, fixed for $30 \mathrm{~min}$ in $1 \%$ osmium tetroxide, dehydrated in ethyl alcohol, and embedded for cross sectioning in epoxy resin (Epon 812). The sections, after staining with uranyl acetate and lead citrate, were examined in a Phillips 200 electron microscope.

Mouse strain L (929) cells were grown in Eagle's minimal essential medium supplemented with $10 \%$ inactivated calf serum. Monolayers were prepared in Leighton tubes on small rectangular strips of plastic, which had previously been sterilized by immersion for $30 \mathrm{sec}$ in fuming nitric aci,d followed by thorough washing in $70 \%$ ethyl alcohol. Concentrated virus was introduced onto previously chilled monolayers, which were then held at $4 \mathrm{C}$ for $45 \mathrm{~min}$. The inoculum was removed, and $1 \mathrm{ml}$ of prewarmed serum-free maintenance solution was added to the tubes in a bath at $37 \mathrm{C}$. After $5 \mathrm{~min}$ at $37 \mathrm{C}$, the strips with attached cells were removed, fixed in glutaraldehyde, and processed for electron microscopy as described above.

\section{RESULTS}

One of the major problems encountered in any structural study of parainfluenza virus is pleomorphism. Figure 1 shows a cluster of virions near the surface of an entodermal cell (to the left). Although the entire limiting membrane and peripheral coat (together constituting the "envelope") of some particles are clearly defined, others are so irregular in shape that only portions of the surface components lie perpendicular to the plane of section and hence are clearly visible. Considerable caution must be exercised in attempting to determine whether a given portion of the viral coat has been ruptured or is merely oblique to the plane of section. The number of nucleoprotein filaments within different particles varies. Attachment to the virus of cytoplasmic fragments which had been cast off by the cells and which were free in the chorioallantoic fluid can be seen in the upper right of Fig. 1; this phenomenon was encountered frequently.

Figure 2 shows two large, irregularly shaped virions. The one on the right is near the cell but not attached to it. The virus on the left has merged with the cell so that the interior of the particle is clearly continuous with the cytoplasm. 

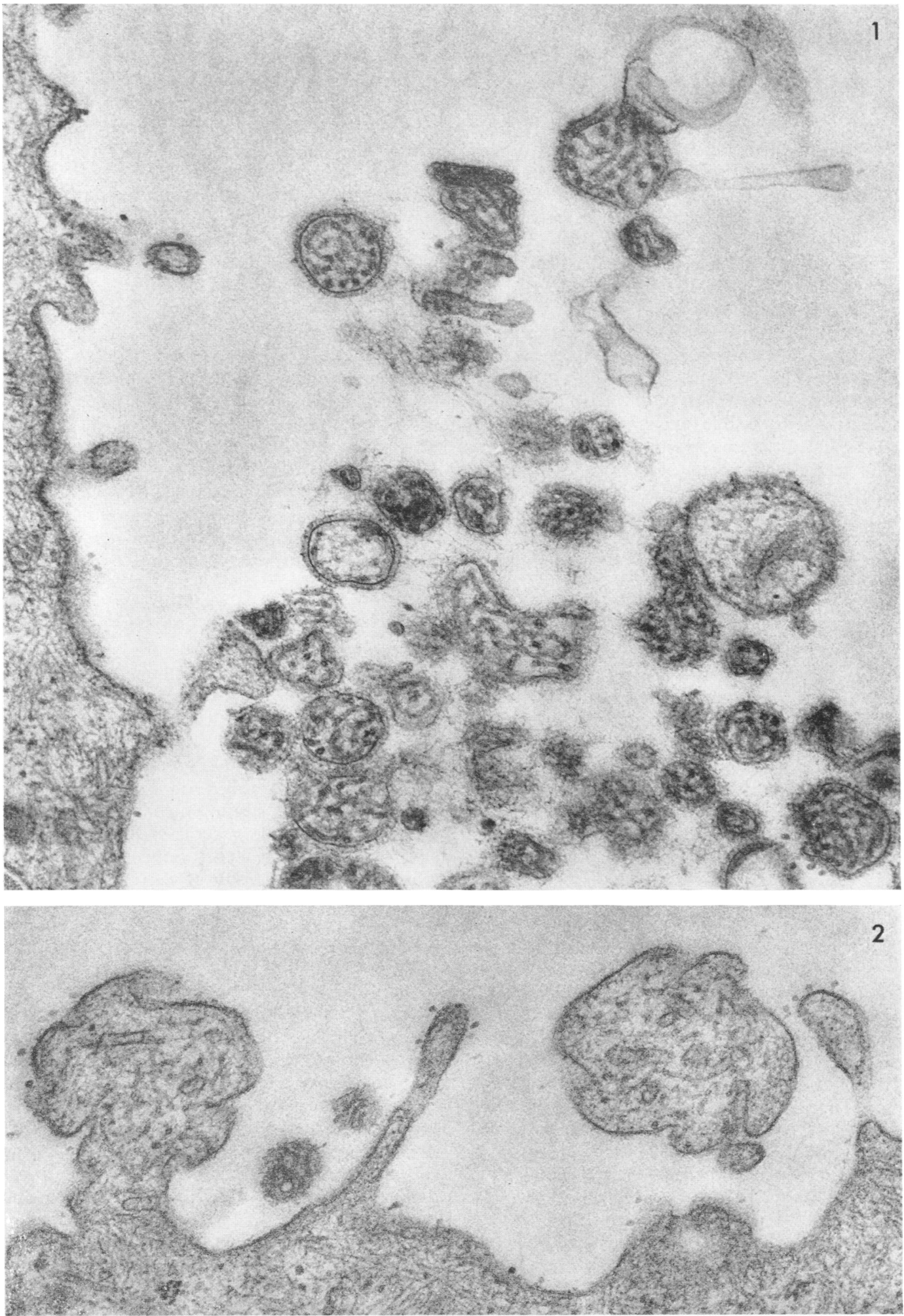

Fig. 1 and 2. Duration of incubation at $37 \mathrm{C}$ after $1 \mathrm{hr}$ at $4 \mathrm{C}$ was $5 \mathrm{~min} . \times 55,000$. 
Stages in the attachment and fusion of the virus are examined in detail below.

Initially, the virus passes through the mucoprotein coating of the cells and comes to lie in proximity with the surface. In Fig. 3, a characteristic virion can be seen close to the cell surface, which does not appear to be altered. It is evident that there are defects in the viral coat, which may be starting to undergo dissolution. In some instances, the virion is distorted as if there were a firm bond at the site of attachment to the cell; this phenomenon was also encountered with herpes simplex virus (7). In Fig. 4, for example, the virion appears to have been pulled out. The low-density coat covering the viral membrane distal to the cell is not present on the proximal portion. A cytoplasmic fragment is attached at the lower right. In cross section, the viral nucleoprotein strands exhibit cores of low density. Figure 5 illustrates another distorted virion, whose coat may be in process of dissolution.

In some cases, the virion indents the cell and there appears to be a layer of material binding the viral coat to the plasma membrane (Fig. 6). In Fig. 7, an irregularly shaped viral particle with attached cytoplasmic fragments has indented the cell. At first glance, one may suspect that the virions shown in the two preceding micrographs are at an early stage in the process of phagocytosis. As is discussed below, however, the plasma membrane does not exhibit the characteristic change which accompanies phagocytosis. Occasionally, the virus attaches to a cytoplasmic extension (Fig. 8). Even under such circumstances, when the site of attachment is confined to only a small part of the surface of the virion, the viral coat may show signs of dissolution.

Fusion of the virus to the cell begins at one site (Fig. 9). (The infoldings of the surface visible in this virion are not uncommon, but their connection with the surface is only evident when they are favorably oriented within the section.) In cases where the virion attaches to a cytoplasmic projection (Fig. 8), fusion occurs at the tip of the projection (Fig. 10; the host cell is to the left). The discrete, dense, globular structures scattered on the surface of this viral particle are probably droplets of protein or lipoprotein; such droplets are commonly encountered in the chorioallantoic fluid and occasionally become attached to the virus or cell surface.

In some cases, filaments of nucleoprotein are observed at a stage of transit into the cytoplasm. In Fig. 11, two filaments extending from the virion through the site of attachment into the c.vtoplasm are clearly visible. Figure 12 shows a more advanced stage with several filaments of characteristic diameter and density in the cytoplasm at some distance from the virion, which is fused to the plasma membrane. In Fig. 13, the locus of viral attachment cannot be identified with certainty, although a collection of nucleoprotein filaments has been released into the cytoplasm.

Not infrequently, irregularly shaped viral particles fuse with the cell at more than one site, leaving the intervening viral and plasma membranes intact. In Fig. 14, the virion is clearly fused with the cell, whereas above and to the right a projection of the virion is in contact with the cell surface. Between these two sites, the surface membrane of the cell and limiting membrane of the virus are clearly evident. In Fig. 15, two sites of fusion are evident. Figure 16 illustrates a situation in which a cytoplasmic protrusion extends outward from the cell in close proximity to a virion which has already fused to another protrusion. Under such circumstances, viral particles which are circular or oval in shape may exhibit two sites of fusion, as seems to be the case in Fig. 17.

Figure 18 shows a virion with an attached cytoplasmic fragment. Just beneath the virion is a phagocytic vacuole. As was noted in earlier studies of influenza virus (6), development of phagocytic vacuoles is heralded by changes in electron density at the sites in the plasma membrane where invagination ultimately occurs. A zone of increased density surrounds part or all of the fully developed vacuole in the cytoplasm. [This phenomenon has been illustrated and described by Palade and Bruns (9).] In Fig. 19, a virion is nearly engulfed; in Fig. 20, another virion, with intact limiting membrane, is lodged within a cytoplasmic vacuole showing the characteristic dense perivacuolar zone. In Fig. 21, the area of increased density bordering the indentation of the cell denotes the impending development of a phagocytic vacuole. At the top of the micrograph, however, the virion has already fused to the cell and there is continuity between the interior of the virion and the cytoplasm.

As is the case with both influenza virus (6) and herpes simplex virus (7), the uncoating process may precede fusion to the cell with consequent rupture and loss of viral contents. In Fig. 22, a virion is attached to the cell surface. At the bottom, near a cytoplasmic fragment, the external coat and limiting membrane of the virion appear to have ruptured. In Fig. 23, nucleoprotein filaments are in process of release into the extracellular space.

In some instances, unusually large virions fuse at multiple sites and several fragments of viral and plasma membrane remain (Fig. 24). In this micrograph, note how perfectly the viral membrane has fused with the plasma membrane at the top, close to an adjoining cell.

In a preliminary study of $\mathrm{L}$ cells, the process of 

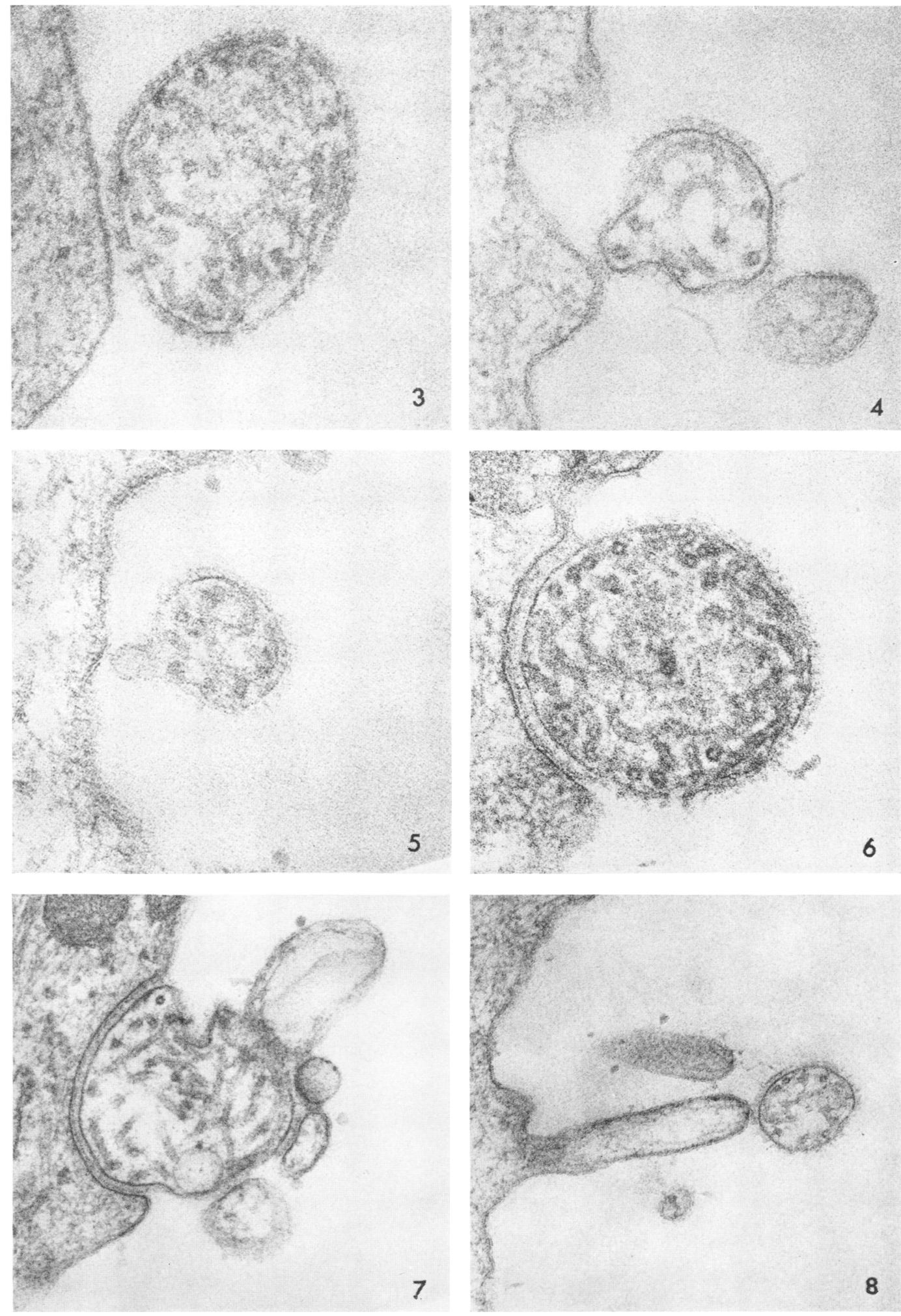

Fig. 3-8. Duration of incubation at $37 \mathrm{C}$ after $1 \mathrm{hr}$ at $4 \mathrm{C}$ was (3) $5 \mathrm{~min}$, (4) $2 \mathrm{~min}$, (5) $5 \mathrm{~min}$, (6) $4 \mathrm{~min}$, (7) 0 min, (8) 5 min. Fig. 3-6, $\times 120,000 ;$ Fig. 7 and $8, \times 66,000$. 

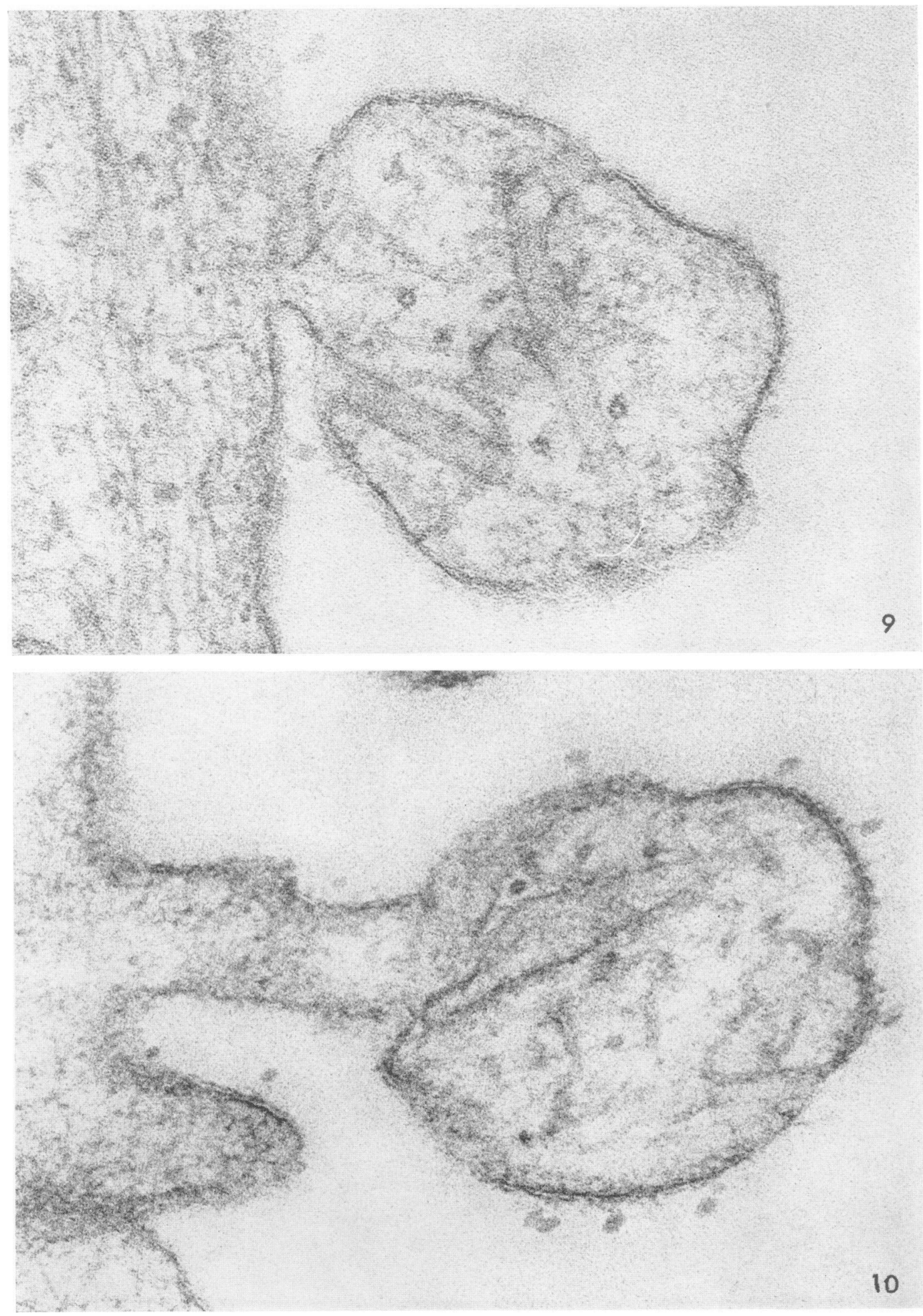

Fig. 9 and 10. Duration of incubation at $37 \mathrm{C}$ after $1 \mathrm{hr}$ at $4 \mathrm{C}$ was $5 \mathrm{~min} . \times 140,000$. 

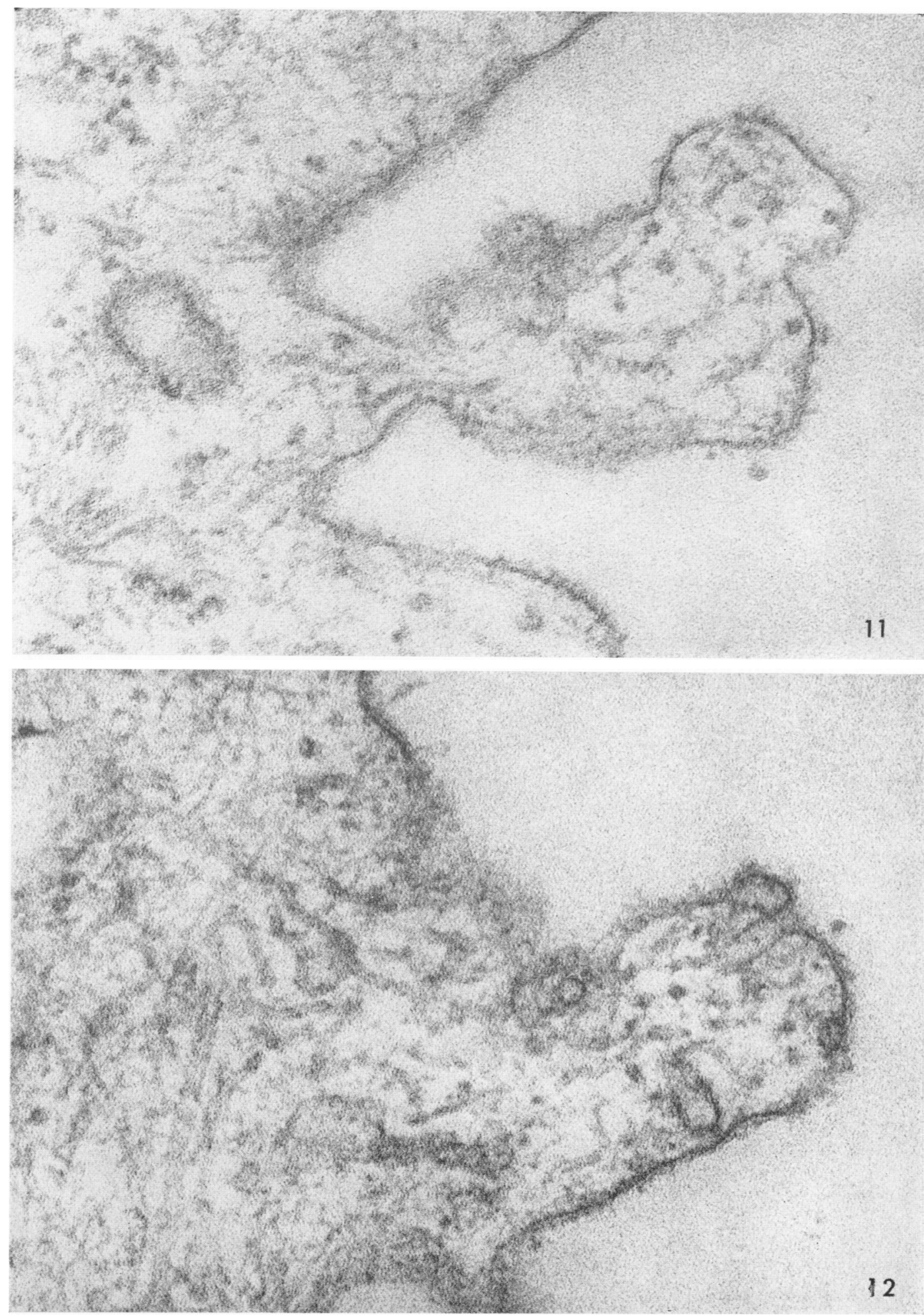

Fig. 11 and 12. Duration of incubation at $37 \mathrm{C}$ after $1 \mathrm{hr}$ at $4 \mathrm{C}$ was $5 \mathrm{~min} . \times 140,000$. 

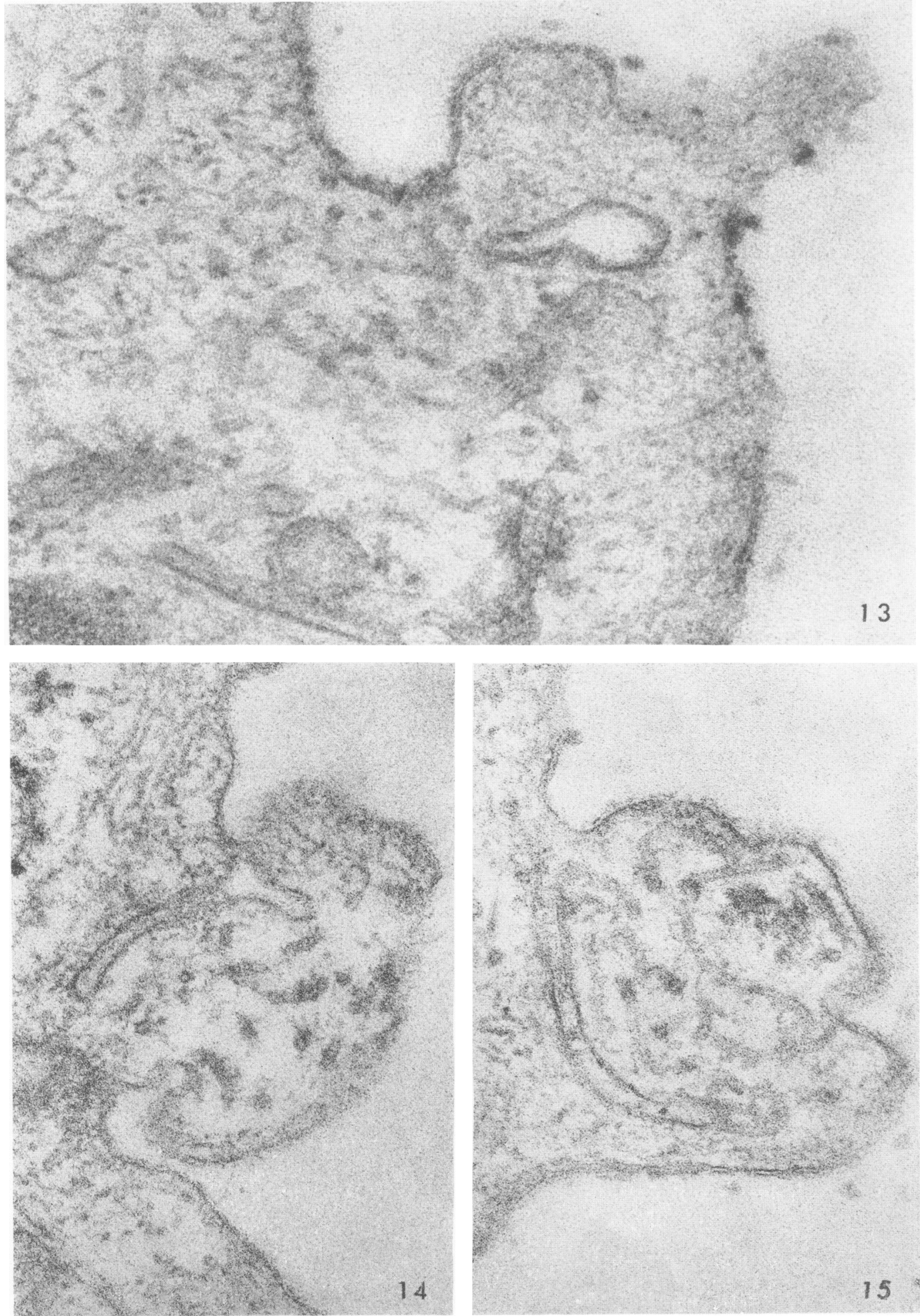

Fig. 13-15. Duration of incubation at $37 \mathrm{C}$ after $1 \mathrm{hr}$ at $4 \mathrm{C}$ was (13) $10 \mathrm{~min}$, (14) 2 min, (15) 6 min. Fig. 13, $\times 140,000$; Fig. 14 and 15, $\times 120,000$. 

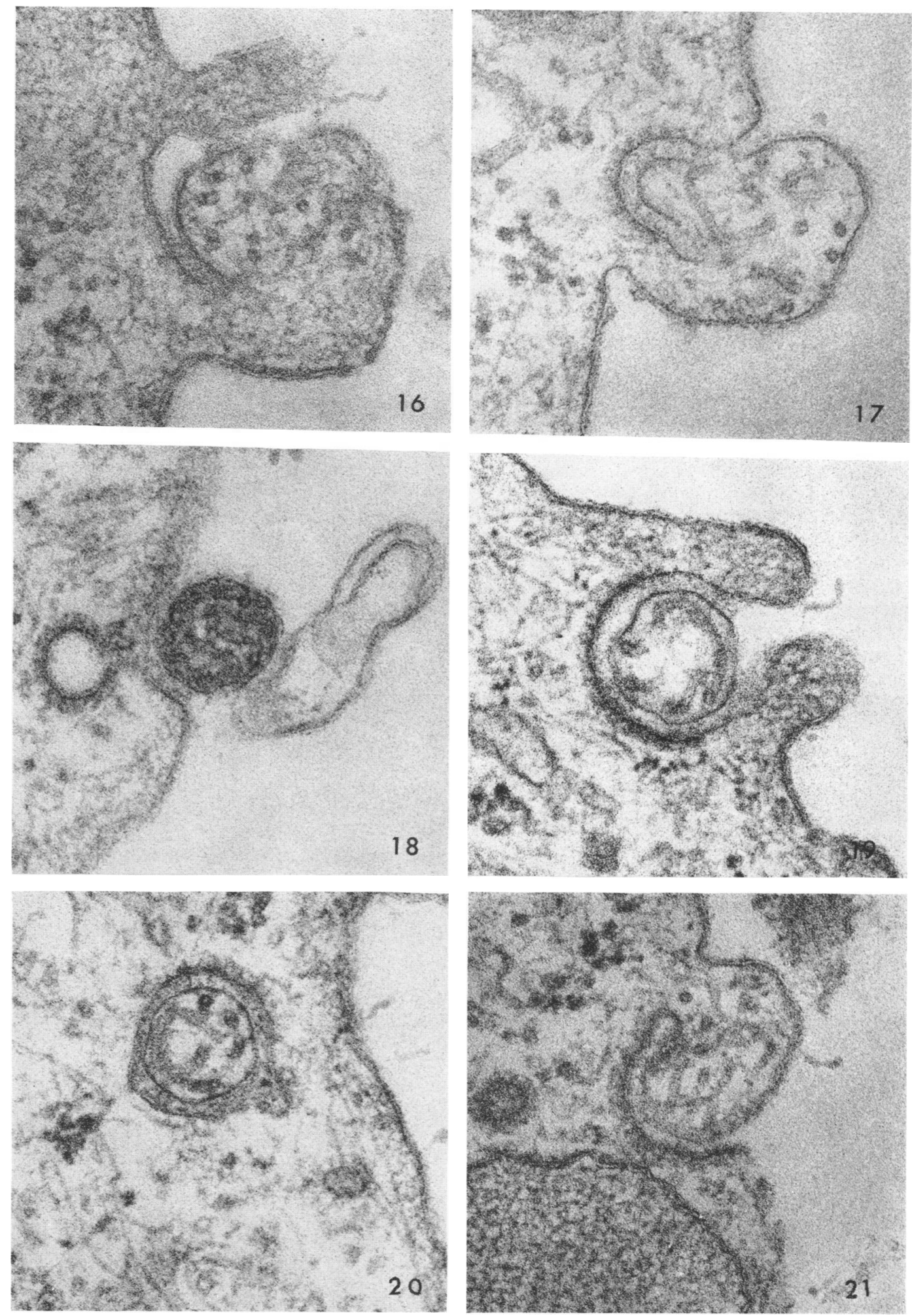

Fig. 16-21. Duration of incubation at $37 \mathrm{C}$ after $1 \mathrm{hr}$ at $4 \mathrm{C}$ was (16) $4 \mathrm{~min},(17) 6 \mathrm{~min},(18) 0 \mathrm{~min},(19-21), 4$ min. $\times 120,000$. 
uncoating, fusion, and entry of nucleoprotein filaments was indistinguishable from that observed to occur at the surface of the chorioallantoic membrane. In Fig. 25, two virions are shown at the surface of an $L$ cell. The virion on the right appears to be in the process of uncoating, although fusion with the cell is not evident. On the left, however, continuity of the virion and cell is clearly seen, and a nucleoprotein filament appears to be in transit from virus to cytoplasm.

\section{Discussion}

In a study of the interaction between chickenadapted Newcastle disease virus (NDV) and Ehrlich ascites tumor (EAT) cells, Prince and Ginsberg noted the rapid disappearance of inoculated, infective virus from the surface of the cells (10). These investigators hypothesized that the virus either became denatured or disintegrated before or after penetration. That penetration of at least some of the inoculum occurred was substantiated by the demonstration, with immunofluorescence, of synthesis of viral antigen in the cytoplasm of EAT cells; however, no hemagglutinin, complement-fixing antigen, or infective viral progeny issued from these cells. In a subsequent study of such "incomplete" NDV by electron microscopy, Adams and Prince (1) presented electron micrographs of virions adsorbed to EAT cells. Although the disappearance of the viral external lamella and the plasma membrane at the point of mutual contact was noted, no further comment was offered as to the significance of these morphological observations. Subsequently, investigators $(2,4,5,13)$ suggested that fusion of virus with the plasma membrane is the mode of myxovirus penetration into animal cells. Okada et al. (8) showed that fusion of Ehrlich ascites cells by Sendai virus is energydependent; they postulated that the process of fusion follows rupture of contiguous cell walls produced by virus interspersed between them. More recently, Hosaka and Koshi (3), in an electron microscopic study, examined Ehrlich ascites cells warmed to $37 \mathrm{C}$ after adsorption of Sendai virus in the cold for $20 \mathrm{~min}$. They observed that within 1 to 2 min "the cell membrane in contact with the envelope of an adsorbed virion often disappears along a limited portion of the virion surface," and concluded "that the virion has some degrading effect on the cell membrane at 37 C." These authors, however, did not report fusion of virions to the cell and suggested that the nucleoprotein filaments gained access to the cytoplasm from phagocytic vesicles, although they were not able to show the stages in this process. Thus, although both direct and indirect evidence has been adduced for the mutual alteration of adsorbed virions and cell surface, the sequential stages in the process have not been described previously. Recent observations with influenza (6) and herpes viruses (7) and those presented here with Sendai virus clearly show that fusion, which establishes continuity between viral core and cytoplasm, constitutes the mechanism whereby the genome of these viruses with lipoprotein envelopes gains entrance into the cell.

In contrast to influenza virions, which tend to be spheres of nearly uniform size, those of Sendai virus vary greatly in dimension and shape. Therefore, it is frequently impossible to be sure about the state of the limiting membrane at any given site. Thus, for example, one cannot be certain whether the right hand portion of the membrane of the virion illustrated in Fig. 7 is at an early stage of dissolution or is poorly defined simply because it is slightly oblique to the plane of section. This disadvantage in the study of Sendai virus, however, is more than offset by the striking fusion of viral membrane to cytoplasmic membrane which can be clearly visualized, and by the relative stability of the nucleoprotein filaments, which, unlike the nucleoprotein of influenza virus, are readily observed at stages in transit from the virus to the cytoplasm.

An interesting aspect of the fusion phenomenon is illustrated in Fig. 14 and 15; in each of these figures, a viral particle is fused to the cell surface at at least two points, between which lie unaltered, but apposed, segments of plasma and viral membrane. This suggests the possibility that the distribution of the surface receptors may not be uniform and that a viral particle the size of Sendai may be sufficiently large and asymmetrical to bridge two or more receptor areas.

As in the case of influenza virus, the speed of uncoating and fusion is remarkable. Figure 14, for example, shows that continuity was established between virion and cytoplasm within 2 min of warming the preparation to $37 \mathrm{C}$. Any enzyme which might be responsible for uncoating the virus, a possibility suggested by Zhdanov (11, 12 ), would have to be preformed, since it is exceedingly unlikely that it could be synthesized in such a short time. The attachment of Sendai virus to mammalian cells is accompanied by the loss of $N$-acetyl-neuraminic acid from the membrane as a result of the action of viral neuraminidase on the receptor sites (unpublished data). It is far from certain, however, that neuraminidase is involved in breaching the plasma membrane, and its role in fusion of viral and cellular membranes, if any, is even less clear. Intact virions within cytoplasmic vacuoles presumably still retain 

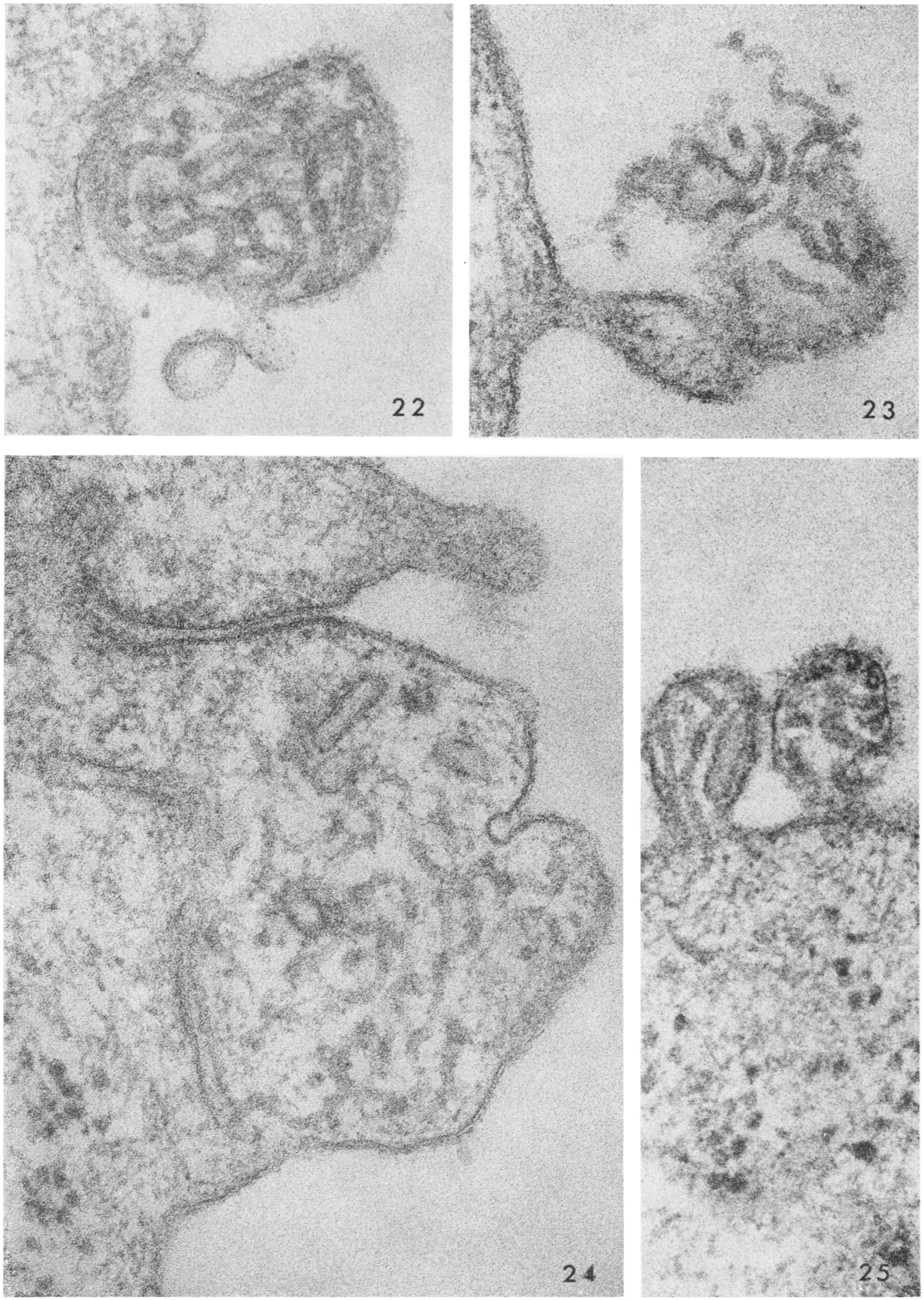

Fig. 22-25. Duration of incubation at $37 \mathrm{C}$ after $1 \mathrm{hr}$ at $4 \mathrm{C}$ was (22) $2 \mathrm{~min}$, (23) $6 \mathrm{~min}$, (24) $4 \mathrm{~min}$, (25) 5 $\min . \times 120,000$ 
neuraminidase activity. Such viral particles, however, do not exhibit fusion with the internal aspect of the vacuoles, suggesting that viral neuraminidase is not accountable for the fusion of virus to the cell periphery.

Whether enzymes are responsible for the uncoating of virus and dissolution of the plasma membrane or whether some other mechanism is involved, such as direct interaction of lipoprotein constituents, must await further study. It is of interest, in this connection, that fusion of parainfluenza virus with the cell is similar to the fusion of vesicle membranes with the plasmalemma, a phenomenon which was recently examined by Palade and Bruns (9) as part of a detailed study of vesicle transport in endothelial cells.

\section{ACKNOWLEDGMENTS}

We thank Elizabeth Newcomb, Baiba Mednis, and Fé M. Reyes for excellent technical assistance.

This investigation was supported by Public Health Service grants AI-06814 and AI-03168 from the National Institute of Allergy and Infectious Diseases; support was also provided by the U.S. Army Medical Research and Development Command, Department of the Army (contract No. DADA 17-67-C-7141) under the sponsorship of the Commission on Influenza, Armed Forces Epidemiological Board.

\section{Literature Cited}

1. Adams, W. R., and A. M. Prince. 1957. An electron microscopic study of incomplete virus formation. Infection of Ehrlich ascites tumor cells with "chick embryo-adapted" Newcastle disease virus (NDV). J. Exptl. Med. 106:617626.

2. Cohen, A. 1963. Mechanism of cell infection. I. Virus attachment and penetration in mechanisms of virus infection, p. 153-199. In W.
Smith (ed.), Mechanisms of virus infection. Academic Press, Inc., New York.

3. Hosaka, Y., and Y. Koshi. 1968. Electron microscopic study of cell fusion by HVJ virions. Virology 34:419-434.

4. Hoyle, L. 1962. The entry of myxovirus into the cell. Cold Spring Harbor Symp. Quant. Biol. 27:113-121.

5. Meiselman, N., A. Kohn, and D. Danon. 1967. Electron microscopic study of penetration of Newcastle disease virus into cells leading to formation of polykaryocytes. J. Cell Sci. 2: 71-76.

6. Morgan, C., and H. M. Rose. 1968. Structure and development of viruses as observed in the electron microscope. VIII. Entry of influenza virus. J. Virol. 2:925-936.

7. Morgan, C., H. M. Rose, and B. Mednis. 1968. Electron microscopy of herpes simplex virus. I. Entry. J. Virol. 2:507-516.

8. Okada, Y., F. Murayama, and K. Yamada. 1966. Requirement of energy for the cell fusion reaction of Ehrlich ascites tumor cells by HVJ. Virology 27:115-130.

9. Palade, G. E., and R. R. Bruns. 1968. Structural modulations of plasmalemmal vesicles. J. Cell Biol. 37:633-649.

10. Prince, A. M., and H. S. Ginsberg. 1957. Immunohistochemical studies on the interaction between Ehrlich ascites tumor cells and Newcastle disease virus. J. Exptl. Med. 105:177-188.

11. Zhdanov, V. M. 1963. The mechanism of penetration of virus particles into cells. Proc. Intern. Congr. Microbiol., 8th, Montreal, 1962. Univ. of Toronto Press, Toronto, Canada.

12. Zhdanov, V. M., and A. G. Bukrinskaya. 1962. Studies on the initial stage of virus-cell interaction. Acta Virol. (Prague) 6:105-113.

13. Zhdanov, V. M., A. G. Bukrinskaya, and G. P. Ramenskaya. 1963. Autoradiographic study of the penetration of Sendai virus into the cell. III. Use of virus preparations labelled with uracil- $\mathrm{C}^{14}, \mathrm{P}^{32}$, methionine-S $\mathrm{S}^{35}$ and cysteine- $\mathrm{S}^{35}$. Acta Virol. (Prague) 7:1-6. 